\title{
Postnatal Drug Withdrawal
}

National Cancer Institute

\section{Source}

National Cancer Institute. Postnatal Drug Withdrawal. NCI Thesaurus. Code C103170.

Withdrawal signs and symptoms that present during the postnatal period and are caused by drug use by the pregnant mother. 